\title{
Gestão estratégica: um exame de práticas em universidades privadas
}

\author{
Victor Meyer Jr. \\ Pontifícia Universidade Católica do Paraná \\ Lucilaine Pascucci \\ Universidade Positivo \\ Lúcia Mangolin \\ Pontifícia Universidade Católica do Paraná
}

\begin{abstract}
A estratégia, como abordagem gerencial, tem se constituído em experiência relativamente recente em organizações universitárias brasileiras. Este artigo tem o objetivo de analisar a prática estratégica em universidades privadas e contribuir com o debate sobre esse tópico que desafia a administração dessas organizações. Trata-se de um estudo comparativo de casos onde é analisada a realidade de duas universidades comunitárias brasileiras. Por meio de questionário e entrevistas, identificaram-se práticas adotadas na gestão estratégica das instituições de educação superior - IES. A análise dos dados revelou que a prática estratégica mescla estratégias deliberadas e, principalmente, estratégias emergentes. As estratégias decorrem tanto de planos formais institucionais quanto de iniciativas individuais e grupais, que resultam de interações, de insights, do feeling, da visão e reação de gestores e docentes diante dos desafios que se apresentam no dia a dia. As estratégias emergem por meio de microestratégias praticadas por gestores acadêmicos e por professores, que atuam como estrategistas. Os resultados apontaram, ainda, para a presença marcante de fatores subjetivos como criatividade, conhecimento tácito, sensibilidade e experiência dos gestores imersos nas práticas estratégicas adotadas na área acadêmica das instituições.
\end{abstract}

Palavras-chave: gestão estratégica; práticas; universidades privadas.

\section{Strategic management: analysis of practices in private universities}

Strategic management is a relatively new approach in the management of Brazilian higher education institutions. This study presents an analysis of strategic practices in two private universities and contributes to the debate over the application of strategy to the field of higher education. This comparative study analyzes the realities of two private universities on the authors use questionnaires and interviews of administrators to capture strategic practices in use. Results of data analysis indicate that strategic practices

Artigo recebido em jul. 2010 e aceito em ago. 2011. 
in both institutions combine deliberate strategies derived from formal plans with emergent strategies from daily practices. Administrators' perceptions of strategies reinforced the existence of planned strategies inserted into formal plans presented by the central administration. At the same time administrators acknowledged the existence of emergent strategies as a result individual and group initiatives based on interactions, insights, feelings, vision, and reaction to challenges they faced during the daily activities. These strategies emerged in both institutions from micro-strategies carried out by academic administrators and professors. The conclusions reveal the existence of influential subjective factors like creativity, tacit knowledge, sensitivity and experience of administrators embedded in the adopted practices.

KEY WORDS: strategic management; practices; private universities.

\section{Introdução}

As instituições de educação superior - IES — brasileiras, a exemplo de outras organizações, têm enfrentado constantes desafios provocados por mudanças no ambiente. Este contexto, no caso das instituições privadas, caracteriza-se por acirrada competição, respostas lentas às demandas externas, grande ênfase no ensino de graduação, busca pela melhoria da qualidade do ensino, baixa produtividade acadêmico-científica e foco na eficiência organizacional.

As IES, em particular as universidades, têm sido pressionadas a reverem sua gestão e buscarem formas mais eficientes e eficazes de atuação. Entre os motivos, destacam-se as constantes mudanças na política educacional, as demandas do setor produtivo, as flutuações na demanda por cursos e as renovadas necessidades e expectativas dos alunos.

Isto tem feito com que estas instituições se lancem à busca de um gerenciamento estratégico que lhes permita melhor definição de objetivos, estabelecimento de prioridades, uso mais adequado dos recursos e, em especial, a materialização das estratégias. Assim, um dos aspectos críticos da gestão universitária tem sido a prática de estratégias que permitam a esse tipo de organização alcançar o desempenho desejado e se manter competitiva no setor.

A área acadêmica tem sido um foco muito rico de ações estratégicas relevantes. Trata-se do locus onde as atividades principais da instituição - ensino e pesquisa - se desenvolvem apoiadas em iniciativas individuais e grupais de professores nas diversas unidades que abrigam os programas acadêmicos. Como destacam Mintzberg e Rose (2007), muitas vezes o processo e a trajetória de estratégias acadêmicas não são muito claros, assim como a forma como se desenvolvem, mudam e impactam o contexto universitário.

Nas universidades brasileiras, esse processo tem se caracterizado por planos estratégicos desenhados com base em modelos e paradigmas racionais inspirados na realidade das empresas. Tais modelos, quando aplicados em organizações universitárias, não apresentam resultados efetivos, por tratar-se de organização onde o processo gerencial mescla aspectos racionais, políticos e simbólicos (Meyer Jr., 2005) para atender interesses dos diferentes públicos da instituição.

O objetivo deste artigo é analisar a gestão estratégica e suas práticas em duas universidades privadas brasileiras. É examinada a extensão em que as estratégias praticadas resultam 
de planos formais ou emergem de ações praticadas nas instituições, bem como o contexto em que ocorrem. Por fim, com base nos resultados encontrados, são analisados os desafios que se apresentam aos gestores desse tipo de organização.

\section{Fundamentação teórica}

\subsection{Estratégia nas organizações}

A literatura sobre gestão estratégica define estratégia como um conceito multifacetado, com diferentes dimensões, tais como pensamento estratégico, processo estratégico e mudança estratégica. A transformação de intenções em ações, em especial, tem se mostrado um grande desafio para os gestores organizacionais.

Estudos têm exaltado uma mecanicidade, racionalidade e previsibilidade que não se aplicam à maioria das organizações tradicionais e que se tornam impraticáveis, em se tratando de sistemas complexos (Axelrod e Cohen, 1999; Stacey, 1996). Mintzberg e Quinn (1991) ressaltam que o processo de formação de estratégias nas organizações raramente se parece com os modelos analítico-racionais destacados na literatura. $\mathrm{Na}$ prática, esse processo costuma ser fragmentado, evolutivo, negociado e intuitivo, tendo sido denominado por Quinn (1978) como "incrementalismo lógico".

Em trabalho que representa um divisor de águas no estudo de estratégias organizacionais, Mintzberg e Waters (1985) identificaram a existência de uma diferença entre "estratégias planejadas" - que podem ou não ser realizadas — e "estratégias emergentes" — que resultam das ações efetivas das organizações e são materializadas por meio de padrões de comportamento ainda não internalizados. A evolução desse processo veio com o termo "formação de estratégias", cunhado por Mintzberg (1990), referindo-se ao processo pelo qual as estratégias são criadas, seja como um processo de planejamento consciente ou um processo de emersão.

Nesse contexto, a formação de estratégias nas organizações resulta da convergência de abordagens racionais e intuitivas e envolvem aspectos políticos, informacionais e comportamentais (Mintzberg e Quinn, 1991). Para Chakravarthy e White (2006), o processo de gestão estratégica engloba longos períodos de tempo, diferentes níveis, processo cognitivo dos tomadores de decisão, processos sociais e psicológicos e, ainda, regras e rotinas organizacionais que orientam e condicionam decisões e ações dentro das organizações.

O caráter interligado desses elementos, associado ao entendimento do agente organizacional como alguém que sente, interpreta e tem interesses, permite a correlação do conceito de estratégia com a adoção de práticas específicas (Veyne, 1997). Nesta perspectiva, as estratégias são entendidas não por aquilo que pretendem ser ou alcançar, mas sim por aquilo que efetivamente se faz ou pratica. Para Veyne (1997:157), prática "is not some mysterious agency, some substratum of history, some hidden engine; it is what people do (the word says just what it 
means)". Assim, estratégias não existem sem que haja um conjunto de práticas, individuais ou não, que formem sua base.

A prática estratégica pode acontecer em diferentes níveis hierárquicos, circunstâncias e contextos organizacionais. Todavia, apenas uma pequena parcela de ações ocorridas pode ser chamada de estratégica por representar um conjunto de práticas, atividades ou rotinas que constituem o que é, formalmente, reconhecido como estratégico (Carter, Clegg e Kornberger, 2008). Nesta perspectiva, ganham destaque aspectos cognitivos, como a interpretação e o sensemaking dos agentes.

Para Perrow (1986), a abordagem interpretativa destacada por March e Olsen (1976) e por Weick (1979) reforça um aspecto relevante para o entendimento do comportamento humano nas organizações. O fato de a ação preceder a ideia faz com que as interpretações e significados das ações só se revelem depois de praticadas. Nesta perspectiva interpretativa, muito daquilo que se pratica no campo gerencial só é compreendido e adquire maior relevância ex post facto.

Nesse contexto, um aspecto importante é o fato de as estratégias emergentes serem absorvidas pela gestão das organizações por meio de uma "racionalidade retrospectiva" (Pfeffer, 1987). Refere-se a ações desenvolvidas e não planejadas serem, retrospectivamente, interpretadas e relacionadas a objetivos e metas previamente estabelecidos. Como bem destacou March (1989), nas organizações, em muitas ocasiões indivíduos agem antes de pensar naquilo que está sendo feito.

O trabalho de formação de estratégias nas organizações, por envolver aspectos racionais, emocionais, intuitivos, simbolismos e manobras políticas, não se constitui em atividade simples para os gestores. A materialização de estratégias requer dos gestores uma combinação de conhecimento, experiência, criatividade, sensibilidade, insights, arte e negociação, entre outras habilidades, certamente, mais exigidas e necessárias na gestão de sistemas organizacionais complexos.

A partir da década de 1980, a prática da abordagem estratégica foi gradativamente sendo disseminada em organizações do mercado competitivo. Atualmente, a gestão estratégica pode ser facilmente identificada em outros contextos organizacionais como órgãos governamentais, bancos, igrejas, hospitais, escolas, museus, universidades, organizações sem fins lucrativos, como também em organizações comunitárias. Todavia, as características específicas fazem com que a prática da gestão estratégica, em muitas dessas organizações, torne-se um desafio ainda maior para seus gestores. É o caso de organizações sociais como universidades, as quais são complexas, surpreendentes, ambíguas e paradoxais.

\subsection{Estratégia em universidades}

As universidades já não são mais um lugar tranquilo onde professores desenvolviam suas atividades de ensino e pesquisa. Neste contexto, de um passado não muito distante, alunos chegavam a fluxos crescentes e contínuos, escolhendo seus cursos e disciplinas. As instituições 
funcionavam em um clima de considerável estabilidade - como requer o ambiente acadêmico — , sendo financiadas por recursos estatais ou privados, alocados de forma sistemática e incremental em seus orçamentos.

Inseridas em um contexto competitivo e de grandes transformações, as universidades privadas têm sido desafiadas em sua capacidade de responder às demandas externas, como forma indispensável de sobreviver, no curto prazo, e de garantir sua sobrevivência, no longo prazo. A adoção de abordagens de gestão como o planejamento estratégico, por exemplo, tem sido cada vez mais crescente nesse tipo de organização. Todavia, a literatura ainda é escassa no que tange a estudos aprofundados, voltados à formação de estratégias em organizações educacionais. As conhecidas diferenças existentes entre organizações empresariais e organizações educacionais possuem grandes implicações na prática da gestão estratégica destas últimas.

Diferentemente de organizações mecanicistas estruturadas com base em modelos racionais, em organizações educacionais os objetivos e estratégias são frouxamente articulados entre si (Weick, 1976, 1979; Orton e Weick, 1990). Para Weick (1976), as organizações educacionais são sistemas frouxamente articulados, o que se constitui fator diferenciador desse tipo de organização. O fato de seus agentes compartilharem alguns poucos pontos comuns e, ao mesmo tempo, manterem sua independência e autonomia, apresenta claras implicações no desempenho dessas organizações e na forma como são gerenciadas.

Embora a adoção da abordagem estratégica pelas IES tenha se intensificado a partir da década de 1990, autores como Kotler e Murphy (1981), Baldridge (1983), Keller (1983), Meyer Jr. (1991), Hardy e Fachin (1996) e Birnbaum (2000) já reforçavam a importância do planejamento e da gestão estratégica para as organizações universitárias, contudo, com ressalvas sobre sua prática neste tipo de organização.

A gestão estratégica praticada em universidades brasileiras tem tido associada, em geral, à chegada de um novo reitor ou de uma nova administração, e sua prática está quase sempre associada à elaboração de um plano estratégico. Este, por sua vez, refere-se a um documento formal, de caráter político e institucional, que serve de referência e justificativa para as principais ações organizacionais, além de cumprir o papel de legitimar as intenções da nova administração perante a comunidade acadêmica.

Contudo, essa prática tão comum nas universidades não tem sido suficiente para produzir e materializar as estratégias exigidas por um contexto tão dinâmico. Fatores como imprevisibilidade e incertezas do ambiente externo, associados a elementos como estrutura frouxamente articulada em uma organização onde o trabalho essencial é desenvolvido por profissionais especialistas, têm se constituído em desafio aos gestores universitários.

O que a prática da gestão estratégica em universidades tem revelado é a existência de um hiato entre planos formais e efetiva prática das estratégias. Duas razões principais podem ser apontadas para justificar esse hiato. Uma primeira razão refere-se ao fato de haver diferenças fundamentais entre organizações empresariais e universidades. Modelos e abordagens gerenciais desenvolvidos para as primeiras dificilmente poderão ter grande utilidade na gestão das segundas. 
Para Weick (1982), alguns pressupostos racionais desses modelos - como objetivos consensuais, relações claras de causa e efeito - não estão presentes na realidade das organizações educacionais, o que inviabilizaria qualquer esforço no sentido de utilizar os mesmos modelos para contextos muito diferentes. Dessa forma, organizações educacionais não podem ser gerenciadas como outras organizações, pois há a necessidade de se levar em conta suas características especiais.

Uma segunda razão pode ser atribuída ao amadorismo gerencial presente nas organizações acadêmicas. Os gestores destas organizações são, em geral, escolhidos muito mais por sua breve experiência como ocupantes de cargos na gestão acadêmica, gerenciando seus pares, do que por reconhecidas habilidades e experiência na gestão de complexas organizações acadêmicas.

Uma prática comum por parte da administração de universidades tem sido a imitação de modelos gerenciais adotados por outras IES, ainda que inexistam claras evidências de eficácia da inovação adotada (Birnbaum, 2000). Entretanto, como aponta Birnbaum (2000), as variáveis estratégicas mais importantes para as organizações universitárias - como preço, localização e programas acadêmicos - não estão sob controle das IES. Assim, o resultado da prática do planejamento estratégico tende a ser superficial e frustrante, constituindo-se em foco de desilusão para os gestores universitários e stakeholders.

Na percepção de Meyer Jr. (2003), são algumas similaridades entre a organização "universidade" e a empresa que têm feito com que modelos e abordagens sejam importados da área de negócios pelas universidades. Por outro lado, como destaca o mesmo autor, são as grandes diferenças entre esses dois tipos de organização que recomendam cautela no uso de ferramentas gerenciais criadas, inicialmente, para uso em empresas. Afinal, como argumentou Mintzberg (1994:13), "estratégias organizacionais não podem ser criadas com base na lógica utilizada na montagem de automóveis".

A inexistência de uma teoria própria de administração universitária tem feito com que as universidades busquem modelos e paradigmas gerenciais no setor empresarial. Assim, pode-se observar, atualmente, uma forte e crescente tendência entre as instituições privadas de educação superior em se identificarem como "empresa". Esse tipo de argumentação tem justificado a incorporação de modelos de gestão empresarial nas práticas gerenciais, fenômeno este identificado como managerialism.

Orientada por princípios de racionalidade, e tendo como foco maior a produtividade e a busca de resultados econômico-financeiros, a prática de modelos empresariais, além de resultados limitados, tende a distanciar as IES de seus objetivos e de sua missão institucional: o papel social e o educacional. Contudo, para que as universidades possam responder aos desafios que lhes impõem um novo contexto econômico, social e tecnológico e se manterem atuantes num ambiente competitivo, torna-se necessário que tais organizações estejam dotadas de uma gestão eficaz. A gestão dessas organizações deve, efetivamente, contribuir para a produção, aplicação e transmissão do conhecimento, tendo como principal beneficiário a própria sociedade que as mantém e legitima. 
Um dos grandes obstáculos enfrentados pelos gestores universitários tem sido integrar pensamento e ação estratégica. Como sistemas abertos, as organizações universitárias estão sujeitas às influências de forças externas que impactam em seu direcionamento e gestão estratégica.

Fundamental para que o esforço de gestão estratégica produza resultados concretos é rever esse processo estratégico nas universidades de forma a melhor integrar o pensar e o agir, combinando decisões da administração e práticas estratégicas individuais e grupais da área acadêmica. É conhecida a dificuldade de integrar a visão e decisões da administração superior com as decisões e ações efetivas nos demais níveis organizacionais, em especial, o acadêmico. Certamente aqui reside uma das maiores dificuldades dos gestores dessas instituições.

Para Hardy e colaboradores (1983:409), não se pode concluir que ações são importantes porque são controladas pela administração superior ou mesmo desconsiderar que ações não são importantes por estarem sob controle dos professores. Nas organizações, segundo os autores, o mais importante do trabalho estratégico está relacionado àquelas atividades que contribuem, essencialmente, para o cumprimento da missão básica da organização. No caso de universidades, essa atividade se concentra nas mãos dos professores, atuando individualmente.

Com base em estudo do planejamento desenvolvido em universidades brasileiras, Meyer Jr. (2005) identificou três dimensões importantes para a compreensão desse processo: racional, política e simbólica. O planejamento, como ato racional, é caracterizado por ordenar, de forma lógica e sequenciada, os objetivos e as ações. Como ato político, o planejamento requer o apoio dos grupos de interesse e a participação das pessoas. As universidades são arenas políticas onde interagem os interesses das diversas áreas de conhecimento e dos grupos que nelas atuam.

Como ato simbólico, o planejamento, o processo, os planos, a programação, o ritual e a linguagem utilizada no processo de formulação de estratégias são vistos muito mais por aquilo que representam para os membros da organização do que por aquilo que efetivamente contribuem para o desempenho da organização (Meyer Jr., 2005). Na prática gerencial, essas dimensões se mesclam diante de contextos organizacionais distintos, formando uma complexa combinação de abordagens, o que exige habilidades especiais do gestor universitário com implicações na prática das estratégias.

Hardy e colaboradores (1983) destacam que o conceito tradicional de estratégia como um plano ou um conjunto de intenções explicitadas, que precedem ações sujeitas a controle, não reflete o entendimento da formação de estratégia no contexto universitário. Uma visão alternativa que melhor reflete a realidade desse processo nas universidades, segundo os mesmos autores, indica que decisões e ações estratégicas relevantes se caracterizam como deliberadas e emergentes e se manifestam como um padrão consistente ao longo do tempo.

Após analisarem a trajetória da Universidade McGill e suas principais estratégias no período 1829-1980, Mintzberg e Rose (2007) apresentaram um quadro distinto da abordagem convencional, em que a administração estratégica está centrada no topo da hierarquia. Para estes autores, as universidades apresentam fronteiras permeáveis com o ambiente, onde se 
espalham incontáveis estrategistas, estratégias fragmentadas e um enorme número de micromudanças, de pequeno efeito. Em razão da existência de um poder compartilhado, distribuído nas mais diversas áreas da estrutura acadêmica, as principais estratégias nas universidades se localizam muito mais na base da pirâmide organizacional do que no topo da organização (Johnson et al., 2007; Jarzabkowski, 2005).

Sem estratégias apropriadas e participação do público adequado, nesse processo, as universidades perdem competitividade, alunos, recursos e prestígio, comprometendo seu futuro. Quer oriundas do processo de planejamento, quer emergentes da dinâmica da organização e baseadas na criatividade, na visão e no insight de seus gestores, o fato é que o processo de formação de estratégias constitui-se em aspecto crítico que desafia a gestão das universidades.

Para Ginsberg (2011), planos estratégicos praticados nas universidades americanas não têm sido nem planos e muito menos estratégicos. Ginsberg argumenta que o processo de produzir planos nas universidades apresenta alguns aspectos críticos e extremamente negativos, como: a) forma de manifestação de poder de parte da administração superior; b) mecanismo de cooptação; c) símbolo de inutilidade e perda de tempo em razão dos pífios resultados alcançados e da alta rotatividade dos principais dirigentes responsáveis pelo processo e pela instituição; d) falta de correspondente suporte orçamentário para os objetivos e estratégias inseridas nos planos.

Fatores como esses têm provocado, segundo Ginsberg (2011), um processo de "corporatização" das universidades americanas e uma consequente redução da influência do corpo docente, fato que tem conduzido a uma perda do rigor intelectual do trabalho das instituições. Isto requer uma reflexão sobre as abordagens gerenciais praticadas nas universidades de todo o mundo.

\section{Metodologia}

\subsection{Design da pesquisa}

Esta pesquisa caracteriza-se como um estudo comparativo de casos, de natureza descritiva (Yin, 1987; Selltiz et al., 1975). O nível de análise é o organizacional e a unidade de análise, a percepção de gestores a respeito da prática estratégica nas universidades pesquisadas.

Para Bruyne e colaboradores (1991:228), “o interesse dos estudos comparativos de casos reside na ultrapassagem da unicidade e na evidenciação de regularidades ou de constantes entre várias organizações cujas semelhanças e dessemelhanças são analisadas". Neste artigo, o foco de análise concentrou-se na gestão estratégica e práticas adotadas em duas universidades privadas brasileiras do tipo comunitário, identificadas como universidade A e universidade B. As principais características das IES foco de estudo são apresentadas a seguir. 
Quadro

Perfil das universidades pesquisadas

\begin{tabular}{|lll|}
\hline Característica & \multicolumn{1}{c}{ Universidade A } & \multicolumn{1}{c|}{ Universidade B } \\
\hline Fundação & 1953 & 1959 \\
Número de alunos & 5.000 & 23.000 \\
Número de professores & 350 & 1.300 \\
Número de colaboradores adminis- & 280 & 1.700 \\
trativos & 46 cursos de graduação & 53 cursos de graduação \\
Número de cursos ofertados & 1 mestrado & 12 mestrados \\
& 1 doutorado & 4 doutorados \\
\hline
\end{tabular}

Fonte: Website das IES. Dados de 2010.

A universidade A é uma instituição privada, católica e comunitária. Foi fundada em 1953 como faculdade de filosofia, ciências e letras, transformada em faculdades integradas em 1980, e reconhecida como universidade em 1986. Localizada no estado de São Paulo, destaca-se no cenário da educação superior regional por seu desempenho educacional, acadêmico-científico e ações comunitárias. A universidade localiza-se num único campus e desenvolve suas ações em área geográfica onde atuam também outras instituições de educação superior, com quem compete.

Localizada no estado do Paraná, a universidade B é uma instituição privada, católica e comunitária. Trata-se de uma universidade tradicional, de médio porte, estruturada em um sistema multicampi, com unidades em diversas regiões do estado. A universidade sofre intensa competição de universidades e outras IES que atuam na região. A universidade possui um planejamento estratégico de longo prazo, cujas estratégias são, em sua maioria, postas em prática pela administração da universidade.

\subsection{Fonte e coleta dos dados}

Foram três as principais fontes de coleta de dados: questionário, entrevista e documentos. Estas fontes foram definidas para evitar possíveis vieses, comuns quando utilizada fonte única (Eisenhardt, 1989; Denzin e Lincoln, 1994; Yin, 1987). A coleta dos dados primários somou 12 entrevistados e 44 respondentes, totalizando 56 participantes de nível superior, intermediário e operacional das IES, entre eles, alta administração, gestores acadêmicos e professores. O critério de amostragem, tanto para as entrevistas quanto para a aplicação dos questionários, foi intencional (Kidder, 1987), por focar gestores diretamente envolvidos na gestão estratégica das organizações.

O questionário semiestruturado, composto por 23 questões, foi aplicado a 21 gestores da universidade A e a 23 gestores da universidade B e teve como objetivo captar a percepção 
desses gestores a respeito da gestão estratégica, suas práticas e resultados dela decorrentes. Adotou-se a "entrevista guiada" para aprofundar a investigação a respeito da gestão estratégica das IES, bem como explorar situações apontadas por gestores durante a aplicação dos questionários. Foram entrevistados seis gestores de cada universidade foco de estudo. Os instrumentos foram previamente testados e validados em IES diferentes das estudadas.

Também foram acessados e analisados dados secundários, como os planos estratégicos das IES, relatórios internos e outros, disponibilizados nos sites das IES. As informações coletadas foram organizadas e tratadas por meio de técnicas de análise documental, tendo os dados dos questionários sido tratados utilizando-se estatística descritiva. A variedade de métodos utilizados na obtenção e análise permitiu a triangulação dos dados, recomendada por Yin (1987) e Eisenhardt (1989) para garantir a validade das informações obtidas.

\section{Análise dos dados}

O ponto central deste artigo e um dos temas mais importantes da gestão de universidades, em especial as privadas, é a prática estratégica. Uma vez que tais organizações apresentam características diferentes de organizações empresariais, para as quais os modelos de gestão estratégica foram concebidos, buscou-se identificar, por meio da percepção dos gestores, o significado de estratégia e suas práticas nas IES. Na tabela a seguir é apresentada a percepção dos gestores a respeito do conceito de estratégia.

Tabela 1

Conceito de estratégia

\begin{tabular}{|lcccc|}
\hline \multicolumn{1}{|c}{ Estratégia institucional } & $\begin{array}{c}\text { Qtde. } \\
\text { "A" }\end{array}$ & $\begin{array}{c}\text { Qtde. } \\
\text { "B" }\end{array}$ & $\begin{array}{c}\text { Freq. } \\
\text { "A" }\end{array}$ & $\begin{array}{c}\text { Freq. } \\
\text { "B" }\end{array}$ \\
\hline Decisões tomadas & - & 1 & - & 4,3 \\
Conjunto de planos & 16 & 8 & 76,2 & 34,8 \\
Posicionamento da instituição & 1 & 8 & 4,8 & 34,8 \\
Conjunto de decisões e ações & 4 & 6 & 19 & 26,1 \\
Outro & - & - & - & - \\
& \multicolumn{1}{c}{ Total } & 21 & 100 & 100 \\
\hline
\end{tabular}

Fonte: pesquisa.

Observou-se que para 76,2\% dos respondentes da universidade A, estratégia significa um "conjunto de planos" desenvolvido pela instituição, enquanto para $19 \%$ dos gestores, a estratégia organizacional é entendida como um "conjunto de decisões e ações da gestão". Na universidade B houve maior diversidade e para 34,8\% de seus gestores a estratégia organiza- 
cional é um "conjunto de planos", enquanto para outros 34,8\% dos gestores estratégia representa "posicionamento da instituição".

Verificou-se que, para a maioria dos respondentes das universidades foco do estudo, estratégia é um conjunto de planos ou posicionamentos que orientam a ação organizacional e caracterizam seu comportamento no contexto em que atuam. Contudo, em universidades, como apontado por Meyer Jr. e Lopes (2006), a formulação e a implementação de estratégias são processos, essencialmente, separados um do outro. Isto pode ser justificado como uma prática comum nas instituições estudadas e também pelo fato de a entidade mantenedora e a administração superior, em geral, definirem as principais estratégias e as comunicarem aos níveis inferiores da organização, aos quais cabe executá-las. Tal comportamento reforça a existência de uma dicotomia entre o pensar e o agir nesse tipo de organização e uma abordagem top-down.

Tabela 2

Formação da estratégia

\begin{tabular}{|lcccc|}
\hline \multicolumn{1}{|c}{ Principal estratégia } & $\begin{array}{c}\text { Qtde. } \\
\text { "A" }\end{array}$ & $\begin{array}{c}\text { Qtde. } \\
\text { "B" }\end{array}$ & $\begin{array}{c}\text { Freq. } \\
\text { "A" }\end{array}$ & $\begin{array}{c}\text { Freq. } \\
\text { "B" }\end{array}$ \\
\hline Planos & 4 & 8 & 19 & 34,8 \\
Políticas & 13 & 6 & 62 & 26,1 \\
Análise estratégica & 2 & 6 & 9,5 & 26,1 \\
Ações emergentes & 2 & 3 & 9,5 & 13 \\
Outra & - & - & - & - \\
Total & 21 & 23 & 100 & 100 \\
\hline
\end{tabular}

Fonte: questionário aplicado.

A respeito da principal fonte das estratégias, $62 \%$ dos gestores da universidade A apontaram "políticas institucionais", enquanto 19\% dos respondentes apontaram os "planos institucionais". Observou-se que a percepção dos gestores reflete a forte influência da racionalidade política nas decisões e práticas estratégicas (formação), nos termos de Baldridge (1971), Mintzberg (1985) e Meyer Jr. (2005). Esse comportamento pode ser justificado pelo grande número de professores agrupados em diversas unidades acadêmicas que interagem entre si e com a alta administração, em busca de poder e influência na organização, em especial, em decisões estratégicas que envolvam seus interesses.

No contexto das universidades estudadas pode-se inferir que as políticas institucionais refletem interesses grupais, assim como interesses da própria administração superior. A universidade, como organização complexa (Etzioni, 1964; Kast e Rosenzweig, 1979), reúne diversas áreas do conhecimento e profissionais altamente qualificados, formando grupos de interesse distintos. Nesse contexto, em que as decisões são, essencialmente, colegiadas e políticas (Baldridge, 1971), os interesses se materializam nas estratégias institucionais. 
A divergência de interesses, associada à autonomia que os profissionais detêm no desempenho de suas atividades (Mintzberg, 1994), gera resposta diferenciada aos desafios da universidade, contribui para a não linearidade das iniciativas e reforça a característica da organização educacional como sistema frouxamente articulado, nos termos de Orton e Weick (1990).

Sobre o assunto, observou-se na universidade B, novamente, maior diversidade de opiniões. Para 34,8 \% dos respondentes, os "planos institucionais" corporificam as estratégias da universidade. Entretanto, 26,1\% dos seus gestores entenderam que são as "políticas institucionais" que melhor representam as estratégias. Para igual percentual (26,1\%) dos gestores, as estratégias já são materializadas na análise estratégica, podendo funcionar de duas formas: formatando ações futuras, ou corroborando estratégias já presentes na mente dos gestores, funcionando como a racionalidade retrospectiva identificada por Pfeffer (1987).

Um dos aspectos críticos, no que se refere à gestão das IES privadas, tem sido a forma com que a organização se posiciona diante do mercado competitivo. A percepção dos gestores universitários, quanto aos elementos que influenciam o posicionamento estratégico de suas instituições, é apresentada na tabela a seguir.

Tabela 3

Fatores que afetam o posicionamento estratégico

\begin{tabular}{|lcccc|}
\hline \multicolumn{1}{|c}{ Posicionamento estratégico } & $\begin{array}{c}\text { Qtde. } \\
\text { "A" }\end{array}$ & $\begin{array}{c}\text { Qtde. } \\
\text { "B" }\end{array}$ & $\begin{array}{c}\text { Freq. } \\
\text { "A" }\end{array}$ & $\begin{array}{c}\text { Freq. } \\
\text { "B" }\end{array}$ \\
\hline Planos formais & 12 & 17 & 57,1 & 73,9 \\
Ações emergentes & 17 & 14 & 81 & 60,9 \\
Ações negociadas & 10 & 14 & 47,6 & 60,9 \\
Intuição dos gestores & 2 & 1 & 9,5 & 4,3 \\
Outra & 1 & - & 4,8 & - \\
\hline
\end{tabular}

Fonte: pesquisa.

Nota: considerando-se até duas opções por respondente, por ordem de importância.

Para a grande maioria dos gestores (81\%) da universidade A, o posicionamento estratégico da instituição resulta, principalmente, de "ações emergentes". Ou seja, na percepção dos gestores, as principais estratégias não resultam de programação estratégica, mas sim da prática dos gestores diante dos desafios que se apresentam no dia a dia da organização. Nesse processo, foram destacados elementos como a criatividade, a experiência, os insights, o conhecimento tácito e a ousadia dos gestores na execução de microestratégias.

A análise dos dados evidenciou uma incoerência na percepção dos gestores acerca da gestão estratégica nas IES. Num primeiro momento, a estratégia foi conceituada como um conjunto de planos que se materializa em políticas institucionais. Paradoxalmente, os mesmos gestores indicaram o posicionamento estratégico como resultado de ações emergentes, 
executadas em resposta aos desafios do cotidiano organizacional. Tal constatação permite inferir que o planejamento formal das IES assume um caráter simbólico, nos termos de Meyer Jr. (2005).

Como segunda opção, 57,1\% dos respondentes da universidade A destacaram "planos formais" como fator crítico para o posicionamento estratégico. Destaque-se ainda que, para 47,6\% dos respondentes, o posicionamento estratégico resulta de "negociação", o que reforça a presença da prática da racionalidade política, já identificada anteriormente, ao distinguir a barganha e a negociação entre grupos de interesse atuantes na organização.

Um exame das respostas dos gestores da universidade B revela que, para a maioria $(73,9 \%)$ dos respondentes, o posicionamento estratégico resulta de "planos formais", enquanto $60,9 \%$ dos gestores destacaram "ações emergentes" e "ações negociadas", como importantes influenciadores do posicionamento estratégico das IES. No contexto universitário, em que decidir é uma questão de obtenção de consenso, as habilidades técnicas e políticas do gestor tornam-se essenciais para a consecução das estratégias organizacionais, como ressaltou Keller (1983).

Percebeu-se, nas duas IES estudadas, a preponderância de estratégias que emergem da dinâmica gerencial. Tal constatação reforça o entendimento de Mintzberg e Waters (1985) de que as estratégias organizacionais resultam de ações planejadas e, principalmente, de decisões e ações que acontecem no dia a dia, como parte da dinâmica organizacional. Nesse contexto, evidenciou-se que as interações informais são muito representativas, em ambas as IES, para a obtenção de apoio necessário à execução das estratégias.

O caráter emergente identificado na prática estratégica das IES corroborou, ainda, a constatação de Mintzberg e Rose (2007), quando afirmaram que as estratégias em universidades, em sua grande maioria, concentram-se muito mais na base do que no topo da pirâmide organizacional. Entre os agentes que compõem a base da organização universitária, destacase, principalmente, o professor e seu comprometimento e apoio como essenciais para a prática estratégica institucional, como já ressaltaram Hardy e colaboradores (1983).

Tabela 4

Fonte das estratégias

\begin{tabular}{|l|c|c|c|c|}
\hline \multicolumn{1}{|c|}{ Direcionamento das ações } & $\begin{array}{c}\text { Qtde. } \\
\text { "A" }\end{array}$ & $\begin{array}{c}\text { Qtde. } \\
\text { “' } \mathrm{B}^{\prime}\end{array}$ & $\begin{array}{c}\text { Freq. } \\
\text { "A" }\end{array}$ & $\begin{array}{c}\text { Freq. } \\
\text { "B" }\end{array}$ \\
\hline Decisões passadas & 6 & 8 & 28,6 & 34,8 \\
Feeling & 16 & 11 & 76,2 & 47,8 \\
Reação a cada problema & 16 & 17 & 76,2 & 73,9 \\
Ensaios e erros & 1 & 9 & 4,8 & 39,1 \\
Outra & 3 & 1 & 14,3 & 4,3 \\
\hline
\end{tabular}

Fonte: pesquisa.

Nota: Considerando-se até duas opções por respondente, por ordem de importância. 
Questionados a respeito da origem das estratégias institucionais, os gestores de ambas as universidades apontaram como principais fontes o "feeling" e a "reação a cada problema", ambas caracterizadas pelo subjetivismo e natureza cognitiva presentes em qualquer esforço humano de produção. Para 76,2\% dos gestores da universidade A, "feeling" e "a reação a cada problema que surge" são responsáveis pelo direcionamento das ações, evidenciando a representatividade do componente subjetivo - como o sensemaking - e o caráter emergente de muitas das estratégias implementadas (Weick, 1979; Chaffee, 1985; Stacey, 1996).

Situação semelhante foi observada na universidade B, onde o fator "reação a cada problema" foi destacado por $73,9 \%$ dos gestores como fonte de estratégias, seguido pelo fator "feeling", identificado por 47,8\% dos respondentes como outra fonte de importância considerável. Observa-se, novamente, uma dispersão das fontes, na percepção dos gestores da universidade B, com destaque ainda para fatores como "ensaios e erros" (39,1\%) e "decisões passadas" $(34,8 \%)$.

Os resultados apresentados no estudo destacaram a diferença entre planejamento e pensamento estratégico, tão enfatizado por Mintzberg (1994). Como em outras organizações, observou-se, na gestão das universidades, a existência de um processo de programação estratégica em que estratégias são "planejadas". Em paralelo às estratégias planejadas, evidenciouse uma multiplicidade de estratégias emergentes.

Como foco das estratégias emergentes, evidenciou-se o pensamento estratégico resultante da dinâmica organizacional e do sensemaking dos gestores ao manobrarem, politicamente, necessidades institucionais e interesses individuais e grupais. Somam-se a isto as características e experiências pessoais de seus gestores acadêmicos, e, em particular, de uma participação efetiva de professores com ações (práticas) estratégicas concretas no âmbito acadêmico.

Os dados examinados permitiram identificar uma integração entre plano formal e estratégias desenvolvidas. Na universidade A, tal integração foi percebida pela grande maioria (95\%) dos gestores, enquanto na universidade B uma maioria, menos expressiva (65\%), concordou que há integração entre plano formal e estratégias praticadas.

A análise dos dados, entretanto, revelou uma contradição quanto à integração entre planos formais e estratégias praticadas. Além dos relatos em entrevistas com os gestores, a complexidade inerente às organizações universitárias e o ambiente dinâmico em que atuam evidenciou a estreita integração entre plano formal e prática estratégica como pouco provável. A preponderância de estratégias emergentes e a presença de aspectos subjetivos identificados na prática estratégica das IES estudadas - como feeling, ensaios e erros e reação - corroboram esta constatação.

Outro fator que contribui, substancialmente, para o hiato identificado entre o pensar e o agir estratégico diz respeito à disponibilidade de recursos. Uma vez que planos contêm objetivos e metas que orientam ações futuras, a disponibilidade de recursos torna-se crítica para maior congruência entre o pensar e o agir nas universidades, ao proporcionar condições para materialização das estratégias. Verificou-se que ela também tem se constituído em um dos principais desafios dos dirigentes dessas organizações. A percepção dos gestores, sobre a integração entre estratégia e recursos financeiros, é apresentada na tabela a seguir. 
Tabela 5

Integração entre estratégia e recursos financeiros

\begin{tabular}{|lcccc|}
\hline \multicolumn{1}{|c}{ Integração } & $\begin{array}{c}\text { Qtde. } \\
\text { "A" }\end{array}$ & $\begin{array}{c}\text { Qtde. } \\
\text { "B" }\end{array}$ & $\begin{array}{c}\text { Freq. } \\
\text { "A" }\end{array}$ & $\begin{array}{c}\text { Freq. } \\
\text { "B" }\end{array}$ \\
\hline Efetiva & 18 & 12 & 85,7 & 52,2 \\
Rara & - & 2 & - & 8,7 \\
Ocasional & 3 & 9 & 14,3 & 39,1 \\
Inexistente & - & - & - & - \\
Outra & - & - & - & - \\
Total & 21 & 23 & 100 & 100 \\
\hline
\end{tabular}

Fonte: pesquisa.

Observa-se que 85,7\% dos respondentes da universidade A entenderam que há efetiva integração entre prioridades estratégicas e orçamento, enquanto na universidade B este percentual foi de $52,2 \%$, com outros representativos $39,1 \%$ de gestores que apontaram a integração como, apenas, ocasional.

É comum, em universidades, identificar-se um distanciamento entre prioridades estabelecidas nos planos formais e prioridades de investimento. Entre outros fatores, o suporte orçamentário foi destacado por Ginsberg (2011) como um dos aspectos críticos e extremamente negativos do planejamento estratégico em universidades. Em grande parte, isto ocorre porque, enquanto objetivos e metas do planejamento são frutos de discussões entre área acadêmica e direção superior da universidade, o orçamento, por sua vez, é resultado de negociações entre direção superior e entidade mantenedora (holding).

Ao assumir o controle, mantenedoras detêm a responsabilidade de definir as principais políticas e diretrizes a serem cumpridas pelas IES e, entre elas, inclui-se a decisão sobre alocação de recursos. Como também apontou Ginsberg (2011), este modelo de gestão tem reduzido, cada vez mais, a participação do corpo docente na gestão acadêmica, com perdas significativas em comprometimento e rigor intelectual destes profissionais.

A percepção dos gestores das duas universidades, especialmente, os da universidade A, leva a concluir pela existência de grande integração interna entre unidades, assim como entre instituição e mantenedora. A forte percepção de ocasionalidade desta integração, verificada na universidade $\mathrm{B}$, evidencia que esta IES opera com uma margem de flexibilidade maior, o que não deve ser visto, necessariamente, como um aspecto negativo da gestão. A respeito do assunto, um dos gestores da universidade B apontou que "a gestão estratégica é uma prática importante [...] entretanto, devido à fraca integração entre plano estratégico e plano orçamentário, os resultados deixam a desejar" (relato de entrevista). 
Tabela 6

Resultados práticos

\begin{tabular}{|lcccc|}
\hline \multicolumn{1}{|c}{ Resultados práticos do planejamento } & $\begin{array}{c}\text { Qtde. } \\
\text { “A” }\end{array}$ & $\begin{array}{c}\text { Qtde. } \\
\text { “B” }\end{array}$ & $\begin{array}{c}\text { Freq. } \\
\text { "A" }\end{array}$ & $\begin{array}{c}\text { Freq. } \\
\text { “B” }\end{array}$ \\
\hline Melhoria da qualidade acadêmica & 18 & 15 & 85,7 & 65,2 \\
Maior capacidade de resposta & 15 & 9 & 71,4 & 39,1 \\
Integração & 5 & 10 & 23,8 & 43,5 \\
Melhor aproveitamento & 4 & 11 & 19 & 47,8 \\
Outro & - & 1 & - & 4,3 \\
\hline
\end{tabular}

Fonte: pesquisa.

Nota: Os respondentes deveriam indicar até duas opções, apontando-as por ordem de importância.

Um dos principais fatores que justificam a gestão estratégica, em qualquer universidade, tem sido as contribuições para a eficácia organizacional. Ao serem questionados a este respeito, $85,7 \%$ dos gestores da universidade A declararam que a gestão estratégica contribui para a "melhoria da qualidade acadêmica", enquanto 71,4\% dos respondentes destacaram, como principal benefício, a "maior capacidade de resposta" da universidade aos fatores ambientais. Um dos entrevistados ressaltou que "a gestão estratégica permitiu identificar e definir melhor e com mais segurança os objetivos da universidade, além de aperfeiçoar as ações gerenciais" (relato de entrevista).

Observou-se, na universidade B, uma diversidade de respostas. A maioria $(65,2 \%)$ dos gestores destacou a "melhoria da qualidade acadêmica" como o principal resultado da gestão estratégica, o que evidencia a relevância das práticas estratégicas na gestão acadêmica dos cursos. Para 47,8\% dos gestores, a segunda maior contribuição tem sido o "melhor aproveitamento" dos recursos disponíveis. Nesta resposta, fica implícito o reconhecimento do esforço de racionalidade na prática estratégica ao alinhar objetivos, ações, recursos e resultados. Como terceira opção, foi destacado por 43,5\% dos gestores da universidade B o fator "integração" como importante benefício, em especial, junto à área acadêmica.

Ao comentar os resultados da gestão estratégica, um gestor da universidade B manifestou que "as estratégias funcionam como bússolas, embora muitos gestores ainda as entendam como algo determinístico, que funciona como um relógio" (relato de entrevista). Tal consideração revela a importância da integração na universidade B de um plano de caráter formal e "guarda-chuva", orientando e estimulando as principais ações nas IES. Estas, por sua vez, manifestam-se a partir de interpretações dos objetivos e metas, originando estratégias essencialmente emergentes, e só assim entendidas após sua execução.

A análise das entrevistas permite inferir que, na prática, em ambas as universidades estudadas o caráter emergente predomina na prática estratégica. Constatou-se, ainda, que a implementação das estratégias assume caráter, essencialmente, artesanal — nos termos de Mintzberg (1994). Destacou-se, nesse processo, a representatividade do sistema social em que as estratégias se desenvolvem, como também de características humanas como interpretação 
da realidade e de interesses diversificados, aproximando-se muito do que foi identificado por Whittington (2001) como abordagem sistêmica.

Pode-se reconhecer a dificuldade encontrada por parte dos gestores universitários, de ambas as instituições, em medir o desempenho organizacional. Isto pareceu ocorrer em razão da natureza qualitativa do trabalho acadêmico, da dificuldade de se medir o valor agregado e da interdependência existente entre áreas, setores e unidades acadêmicas que compõem as IES. Contribuem para tal dificuldade a complexidade organizacional e a combinação entre conhecimento, educação e cultura que compõem o produto final e que beneficiam, diferentemente, indivíduos e sociedade. Esforços têm sido desenvolvidos pela gestão de ambas as universidades, no sentido de aprimorar a gestão estratégica e os indicadores de forma a permitir uma melhor avaliação do desempenho institucional.

Observou-se, ainda, um viés no sentido do não reconhecimento dos professores como agentes importantes na prática estratégica das IES estudadas. Entretanto, verificou-se que a condição de independência, de autonomia e de poder desses profissionais torna-os elementos essenciais para o sucesso das estratégias organizacionais. A autoridade profissional, presente nesse tipo de organização, tem suas bases na competência profissional e não na posição hierárquica (Kast e Rosenzweig, 1979; Mintzberg, 1994). Reconhecem-se, portanto, professores como profissionais e importantes estrategistas nesse sistema frouxamente articulado que é a universidade, como identificaram estudiosos como Weick $(1976,1979)$, Birnbaum (1989), March (1989), Orton e Weick (1990), Hardy e colaboradores (1983) e Mintzberg e Rose (2007).

\section{Discussão}

A criação de estratégias e sua materialização constituem-se em objetivo maior de qualquer organização privada que tem como fonte principal de receita as mensalidades escolares, por meio da venda de serviços educacionais no mercado. Este tem sido o caso das universidades privadas brasileiras.

Programadas ou emergentes, as estratégias são indispensáveis para as universidades privadas. Com o propósito de se manterem competitivas, garantirem sustentabilidade ao longo do tempo, satisfazerem as expectativas de seus inúmeros stakeholders e cumprirem sua missão social, as universidades não podem prescindir de estratégias. Estas necessitam ser mais adequadas a suas características, especificidades e cultura e proporcionar um diferencial competitivo e sustentabilidade no longo prazo.

Trata-se de um processo complexo em razão da própria natureza complexa das organizações universitárias. Não se pode desconhecer que as universidades são burocracias (Baldridge, 1971), colegiados (Millet, 1962), arenas políticas (Baldrige, 1971), anarquias organizadas (Cohen e March, 1974) e sistemas frouxamente articulados (Weick, 1976). Como organização profissional, seus professores são agrupados por áreas de conhecimento em unidades acadêmicas onde a autonomia e a liberdade acadêmica para lecionar e pesquisar con- 
stituem-se em fortes valores compartilhados. Definir objetivos, prioridades, alocar recursos e avaliar desempenho são processos complexos que desafiam os gestores universitários.

A análise do processo de formação de estratégias nas universidades estudadas revelou a coexistência de duas abordagens. Uma formal, seguindo modelo racional de gestão estratégica top down e inspirada na prática empresarial, mediante a qual as principais decisões e objetivos são definidos pela administração superior por meio de uma coalizão dominante (Cyert e March, 1963) para toda a organização. Estratégias, nesse caso, caracterizam-se como do estilo "guarda-chuva" (Mintzberg, 1994), servindo como grandes diretrizes a serem efetivamente materializadas nos escalões inferiores, com destaque para a área acadêmica.

Convivendo com o planejamento formal, identificou-se uma segunda abordagem — incremental, informal e emergente — , caracterizada mais pela arte do que pela técnica dos gestores universitários, em que estratégias são originadas e praticadas com base na criatividade e na visão e experiência dos gestores. Sua materialização nas universidades estudadas apresenta-se de forma mais autônoma, flexível e menos integrada e, na maioria das vezes, na forma de microestratégias colocadas em prática por estrategistas que se espalham por diversos níveis, de forma fragmentada, em particular na área acadêmica.

As principais contribuições deste estudo indicam a importância de planos formais, racionais, como orientadores e estimuladores das principais ações. Estes planos coexistem com iniciativas estratégicas da área acadêmica que podem ser vistas não só como desdobramentos das diretrizes institucionais maiores, mas, principalmente, como práticas efetivas relevantes na administração dos cursos e no ensino e pesquisa. Estas demonstraram ser fruto da sensibilidade, visão, insights e iniciativas de gestores e professores. Pode-se observar também que, enquanto para alguns gestores tais práticas emergentes representam a dinâmica e a vitalidade na gestão, para outros representam certo desvio ou mesmo rebeldia ao plano vigente.

Uma vez que ambas as universidades estudadas atuam em um ambiente dinâmico e competitivo que exige respostas rápidas aos novos desafios e, por outro lado, convivem com pesadas estruturas burocráticas e lento processo é muito natural que reações a esses estímulos surjam na forma de estratégias não programadas. Uma das consequências é a prática de estratégias emergentes na área acadêmica, onde o profissionalismo e a liberdade acadêmica são fatores responsáveis pelo agir estratégico na forma de microestratégicas individuais ou de pequenos grupos.

Pode-se observar, nas IES analisadas, que os estrategistas estão em vários setores e níveis das instituições, em especial, na área acadêmica. Observou-se que na universidade $\mathrm{A}$ as relações informais predominantes se constituíram em fonte de maior integração e comunicação entre gestores e professores, contribuindo para o fomento de práticas estratégicas relevantes. No caso da universidade $\mathrm{B}$, o fato de existir uma grande estrutura acadêmica com 53 cursos de graduação e 16 de pós-graduação (mestrados e doutorados) contribuiu para uma maior e mais diversificada prática estratégica. Uma das formas mais praticadas foi a de microestratégias disseminadas em distintos setores da estrutura acadêmica com destaque para a ação estratégica efetiva de professores. 
O fato de muitas iniciativas e ações de gestores acadêmicos e professores não estarem sob controle direto da administração superior não significa que não sejam importantes, como enfatizaram Hardy e colaboradores (1983). Ao contrário, por estarem próximas das atividades de ensino e pesquisa, e, portanto, intimamente ligadas à realização da missão institucional, essas ações se revestem de ainda maior importância para o desempenho organizacional.

O exame e a consideração dos resultados da gestão estratégica praticada em IES podem surpreender muitos gestores universitários. Ao se considerar a complexidade organizacional das universidades, sua missão educacional-social e seu comportamento, tende-se a concordar com Winston (1997) e Birnbaum (2000) quando destacaram que as universidades não são empresas. Isto implica afirmar que abordagens gerenciais modeladas para organizações com fins lucrativos, como as segundas, não se aplicam às primeiras. Portanto, a gestão estratégica na forma praticada nas empresas não se configuraria como adequada à realidade das universidades.

Pensar as universidades privadas tendo como foco a prática de estratégias implica buscar novos componentes para a construção de um modelo próprio e mais adequado às especificidades dessas organizações educacionais. Isto requer uma nova visão sobre sua gestão, o que vale dizer ir muito além da racionalidade gerencial. Sem descartar as orientações e prioridades para a instituição estabelecidas pelos planos, há que se considerar outros elementos relevantes para esse modelo gerencial. A criatividade, essencial para a gestão universitária, o reconhecimento das práticas estratégicas como manifestações individuais e grupais do corpo docente e de gestores acadêmicos integram esse conjunto de componentes de um possível modelo próprio de gestão acadêmica para as universidades.

\section{Conclusões}

Um dos maiores desafios dos gestores de universidades privadas tem sido o pensar e agir estratégicos. Igualmente, necessitam aprender com as práticas adotadas de forma a executar estratégias apropriadas que permitam vencer os atuais obstáculos que hoje desafiam essas organizações, de maneira a contribuir para que possam melhor cumprir sua importante missão.

Uma das principais contribuições deste artigo é reforçar o argumento de que a gestão estratégica praticada em organizações complexas como universidades se reveste de peculiaridades e características próprias não contempladas pelos modelos e abordagens empresariais. Estes têm se mostrado inócuos por não contemplarem as especificidades de universidades, como o fato de serem organizações profissionais e sistemas frouxamente articulados.

Pouca atenção tem sido dada às microações, resultado de práticas individuais de grupos de gestores e professores, que podem se caracterizar como "estratégicas" por influenciar o desempenho institucional. O fato é que a gestão das estratégias nessas organizações constitui-se em tema que carece de estudos mais amplos e sistemáticos que permitam conhecer, com maior profundidade, seus diversos aspectos de natureza processual e comportamental. Somente assim se buscará uma efetiva contribuição para a melhoria do desempenho dessa complexa e relevante instituição social. 
Enfim, a gestão das universidades necessita de profissionais mais qualificados em sua gestão, de estudos mais sistemáticos que analisem efetivamente os benefícios da prática da gestão estratégica. Acima de tudo, são necessárias melhores práticas estratégicas, resgatando os estrategistas disseminados na área acadêmica e suas microações, tão relevantes para o desempenho efetivo dessas instituições.

\section{Referências}

AXELROD, R.; COHEN, M. Harnessing complexity: organizational implications of a scientific frontier. New York: The Free Press, 1999.

BALDRIDGE, J.V. Power and conflict in the university. New York: John Wiley \& Sons, 1971.

BALDRIDGE, J.V. Strategic planning in higher education: does the emperor have any clothes? In BALDRIDGE, J.V.; DEAL, T. The dynamics of organizational change in education. Berkeley: McCutchan, 1983. p. 167-185.

BIRNBAUM, R. How colleges work. San Francisco: Jossey-Bass, 1989.

BIRNBAUM, R. Management fads in higher education. San Francisco: Jossey-Bass, 2000.

BRUYNE, P.; HERMAN, J.; SCHOUTHEETE, M. Dinâmica da pesquisa em ciências sociais. 5. ed. Rio de Janeiro: Francisco Alves, 1991.

CARTER, C.; CLEGG, S.R.; KORNBERGER, M. A very short, fairly interesting and reasonably cheap book about studying strategy. London, EC: Sage, 2008.

CHAFFEE, E.E. Three models of strategy. Academy of Management Review, v. 10, n. 1, p. 89-98, 1985.

CHAKRAVARTHY, B.S.; WHITE, R.E. Stragegy process: forming, implementing and changing strategies. In: PETTIGREW, A.; THOMAS, H.; WHITTINGTON, R. Handbook of strategy and management. London: Sage, 2006. p. 182-205.

CYERT, R.M.; MARCH, J.G. A behavioral theory of the firm. Englewood Cliffs: Prentice-Hall, 1963.

DENZIN, N.K.; LINCOLN, Y.S. Introduction - entering the field of qualitative research. In: DENZIN, N.K.; LINCOLN, Y.S. (Ed.). Handbook of qualitative research. Thousand Oaks: Sage, 1994.

EISENHARDT, K.M. Building theories from case study research. Academy of Management Review, v. 14, n. 4, p. 532-550, 1989.

ETZIONI, A. Modern organizations. New Jersey: Prentice-Hall, 1964.

GINSBERG, B. The strategic plan: neither strategy nor a plan, but a waste of time. The Chronicle of Higher Education, 17, July 2011.

HARDY, C.; FACHIN, R. Gestão estratégica na universidade brasileira: teoria e casos. Porto Alegre: UFRGS, 1996. 
HARDY, C. et al. Strategy formation in the University Setting. Review of Higher Education, v. 4, n. 6, p. 407-433, 1983.

JARZABKOWSKI, P. Strategy as practice: an activity-based approach. London: Sage, 2005.

JOHNSON, G. et al. Micro strategy and strategizing: towards an activity-based view? Journal of Management Studies, v. 40, n. 1, p. 3-22, 2007.

KAST, F.E.; ROSENZWEIG, J.E. Organization and management: a systems and contingency approach. New York: McGraw-Hill, 1979.

KELLER, G. Academic strategy. Baltimore: Johns Hopkins University Press, 1983.

KIDDER, L. (Org.). Métodos de pesquisa nas relações sociais. 4. ed. São Paulo: EPU, 1987. 3 v.

KOTLER, P.; MURPHY, P. Strategic planning for higher education. Journal of Higher Education, p. 470-489, 1981.

MARCH, J.G.; OLSEN, J.P. Ambiguity and choice in organizations. Bergen, Norway: Universitetsforlaget, 1976.

MARCH, J.G. The technology of foolishness. In: MARCH, J.G. Decisions and organizations. New York: Basil Blackwell, 1989.

MEYER JR., V. Planejamento estratégico: uma renovação na gestão das instituições universitárias. In: Temas de administração universitária. Florianópolis: Nupeau, OEA/UFSC, 1991. p. 53-69.

MEYER JR., V. Planejamento universitário: ato racional, político ou simbólico: um estudo de universidades brasileiras. Revista Alcance, v. 12, n. 3, p. 373-389, set./dez. 2005.

MEYER JR., V. Novo contexto e as habilidades do administrador universitário. In: MEYER JR., V.; MURPHY, J.P. Dinossauros, gazelas e tigres: novas abordagens da administração universitária. 2. ed. Florianópolis: Insular, 2003. p. 173-192.

MEYER JR., V.; LOPES, M.C.B. Planeamiento universitario: mito y realidad. Boletín de Investigación Educacional, Santiago, v. 21, n. 1, p. 283-292, 2006.

MILLET, J.D. The academic community. New York: McGraw-Hill, 1962.

MINTZBERG, H.; WATERS, J.A. Of strategies, deliberate and emergent. Strategic Management Journal, v. 6, p. 257-272, 1985.

MINTZBERG, H. Organization as political arena. Journal of Management Studies, v. 22, n. 2, 1985.

MINTZBERG, H. Strategy formation: schools of though. In: FREEDRICKSON, J.W. Perspectives on strategic management. New York: Harper Business, 1990.

MINTZBERG, H. The rise and fall of strategic planning. New York: Freeman, 1994.

MINTZBERG, H.; QUINN, J.B. The strategy process. Englewood Ciffs: Prentice-Hall, 1991. 
MINTZBERG, H.; ROSE, A. Strategic management upside down: McGill University, 1829-1980. In: MINTZBERG, H. Tracking strategies. New York: Oxford University Press, 2007. p. 283-317.

ORTON, J.D.; WEICK, K.E. Loosely coupled systems: a reconceptualization. The Academy of Management Review, v. 15, n. 2, p. 203-223, 1990.

PERROW, C. Complex organizations: a critical essay. Third Edition. New York: McGraw-Hill, 1986.

PFEFFER, J. Organizaciones y teoría de la organización. Buenos Aires: El Ateneo, 1987.

QUINN, J.B. Strategic change: "the logical incrementalism”. Sloan Management Review, v. 1, n. 20, p. 7-21, Fall 1978.

STACEY, R.D. Complexity and creativity in organizations. San Francisco: Berret-Koehler, 1996.

SELLTIZ, C. et al. Métodos de pesquisa nas relações sociais. 5. ed. São Paulo: EPU/Edusp, 1975.

VEYNE, P. Foucault revolutionizes history. In: DAVIDSON, A.I. (Ed.). Foucault and his interlocutors. Chicago, IL: University of Chicago Press, 1997. p. 146-182.

WEICK, K.E. Educational organizations as loosely coupled systems. Administrative Science Quarterly, v. 21, p. 1-19, 1976.

WEICK, K.E. The social psychology of organizing. New York: Random House, 1979.

WEICK, K.E. Administering education in loosely coupled schools. Phi Delta Kappan, v. 63, n. 10, p. 673-675, June 1982.

WHITTINGTON, R. What is strategy and does it matter? London: Cengage Learning, 2001.

WINSTON, G.C. Why can’t a college be like a firm? Change, p. 33-38, Sept./Oct. 1997.

YIN, R. Case study research: design and methods. Beverly Hills: Sage Publications, 1987.

Victor Meyer Jr. é professor do Programa de Pós-Graduação em Administração da Pontifícia Universidade Católica do Paraná (PUC/PR). E-mail: vmeyer@matrix.com.br.

Lucilaine Pascucci é professora titular do Programa de Pós-Graduação em Administração da Universidade Positivo (UP). E-mail: lucilaine.pascucci@gmail.com.

Lúcia Mangolin é mestre em educação pela PUC/PR. E-mail: sabedori@yahoo.com.br. 